\title{
HOW DO YOU FEEL?
}

Preparing novice reporters for the death knock: an exploration of attitudes and approaches

\section{Sallyanne Duncan \& Jackie Newton}

The death knock is a reporting task that presents its own particular pressures. In addition to the usual editorial, legal and ethical concerns, the potential on the part of the journalist to do harm is heightened as they attempt to interview already vulnerable people in a situation which most are ill prepared for. In this environment, reporters are generally expected to learn how to undertake this particular form of sensitive reporting "by doing". Many journalists have received little or no training in this area and despite journalism educators demonstrating a willingness to prepare their students for their first attempt at this type of reporting, there is considerable confusion over the most appropriate and effective methods for doing so. This article discusses certain approaches, specifically role playing, that could be used in the classroom. Firstly, journalists' perceptions of the activity and their preparedness for it were identified in order to enrich educators' understanding of the process. Two studies were undertakena survey of journalists' attitudes to intrusive reporting and interviews with journalists and other interested parties on their perceptions of the death knock and appropriate 
educational strategies. Finally, a focus group of current second and third year students was held to review findings.

\section{Introduction}

When a tragedy occurs, whether it is an incident involving many people or only one family or individual, reporters are invariably sent to interview the relatives of the victims. They generally arrive unexpected and unannounced and their aim is to record the relatives' story, their personal grief and the life of their loved ones. Most of those who find themselves the subject of intrusive reporting are ordinary citizens, who are quite suddenly and without any preparation thrust into the media spotlight. Their loss has made them newsworthy, requiring them to deal with two extremely stressful situations - their grief and invasion of their private life by the media.

Clearly, this is a highly emotional situation and one that requires sensitivity of approach. It is one that journalists in general regard as an unpleasant but necessary part of their job of recording the news of a community. The numbers of paid-for obituaries, death notices and tributes in newspapers and online show a great need in the population for recognition of a loved one's passing, and arguably through the death knock they get this and more as part of the media's public service role. Despite the importance and sensitivity of the task, it is one for which most journalists are ill prepared. Few appear to receive formal training, or indeed advice or instruction from 
senior editorial staff, and whilst most journalism courses now integrate ethical reporting into their curriculum, few actually instruct students in approaches to intrusive reporting or, to use the industry term, a death knock. Indeed, even where intrusive reporting is taught there appears to be considerable confusion over the most effective methods for preparing novice reporters. One of the questions this research seeks to answer is whether young reporters can be reassured about the death knock by having a greater understanding of the ethical issues. Can we give them a sense of control in terms of knowing why they are there, when to approach, what to say, and when to withdraw?

In this paper we provide insight into journalists' perceptions and experiences of intrusive reporting in order to provide a context within which we can discuss the use of role play as a teaching instrument specifically, along with other approaches. In order to do so we surveyed a purposive sample of 126 UK journalists likely to have experience of the death knock on their attitudes to intrusive reporting, gaining 53 substantial responses. We then conducted interviews with 14 editors, victims' representatives, journalism educators and former students - now working as journalists - who had undertaken a death knock. A follow-up focus group was held with eight current students as participants. We also drew on our own knowledge and experience of both the journalism industry and journalism higher education.

\section{Doing the death knock - effects on journalists}


The death knock is arguably one of the most challenging tasks a journalist will perform in his or her career. It comes about through a variety of traumatic situations after road accidents, disasters and murders - and is a controversial but "necessary" part of the reporter's work (Adams, 2001). In the pursuit of news reporters are required to come to terms with the "raw edges of bereavement" as they knock on the door of a grieving family (Dant, 1998). Some reporters may feel they have no choice but to undertake this type of story, and indeed there is legal precedent to say it is part of our job following a 1999 ruling on an unfair dismissal case (Keeble, 2001). Because they are professionals reporters will attempt to do what is asked of them but like most people, they prefer to shun contact with the grieving. Others who believe in the value of intrusive reporting would consider it their duty to cover such stories. As a result, reporters sent to interview a traumatised family can find their professional demands in serious conflict with their personal beliefs.

Harcup (2004) says that to a non-journalist this very act of contacting the bereaved immediately after a tragedy must seem manipulative and callous. However as he points out, when we hear of a disaster or murder we expect the media to provide us with the details of the victims, their names, their ages, and perhaps some indication of who they were and of how they lived their lives. That information does not appear "by magic", or even in the form of a neatly typed press release; it is sought by a journalist knocking at a door. Sometimes those journalists are confident, sometimes competent, but usually they approach with a trepidation bordering on real fear. 
It is noticeable that the literature which exists in this area mainly deals with how journalists operate in times of mass tragedy and trauma, such as in war zones or major terrorist disasters. Little is written about smaller tragedies, where often a journalist is covering the story alone, without a press "pack" or other informal support group to share the experience. This can be an isolating and disconcerting experience for the novice reporter, who may already be unsure of whether their behaviour is appropriate in terms of both the emotional experience of facing bereaved relatives and dealing with the professional challenges of getting the story. Unlike major tragedies where there tends to be a large press pack, reporters who cover the single death knock seldom benefit from any encouragement from fellow journalists who are also covering the event. The nature of the single death knock means reporters arrive at a family's door on an individual basis so there is little opportunity for contact with journalists from rival publications and when there is it tends to be detached rather than supportive. This individual contact can also have an effect on the relatives who are asked to repeatedly tell their story to different journalists as each comes to their door. This can exacerbate the intrusion and harm caused by the journalist, often unintentionally. It can shape how effectively the reporter can complete their task - despite their efforts they may not be able to elicit as valuable a response from the interviewee as journalists who interviewed the family earlier, merely because the interviewee has told the story several times before. Also, there are few, if any, official reporting mechanisms such as press conferences. This ensures that the reporter uses primary sources, which requires them to make contact with the family, friends and neighbours. As a result, the reporter and 
family come face to face in circumstances where the reporter is asking highly personal questions of a particularly vulnerable group, the newly bereaved.

After the traumatic interview the onus is mostly put on the reporter to seek help or share their concerns about the experience, whereas something more formal may be established for a large-scale event. In addition, there is less likely to be a mechanism within the company for debriefing or counselling those who are emotionally disturbed by their experiences. Such facilities are more likely to be provided by a media organisation after a major tragedy. Equally, there seems limited opportunity for the inexperienced reporter to discuss their experience of death knocks with colleagues. The "macho" culture in the newsroom, deemed to be one in which the journalist must give the impression of being detached, desensitized, and in control (Simpson and Cote, 2006; Cameron, 2007), can be an intimidating environment for the novice reporter and thus, may limit the value of such "sharing".

Unlike the police, Victim Support, the medical profession or the clergy, the journalist can offer little acknowledged succour at such times. The ambiguity of the journalist's role in the intrusive situation may cause tension between the reporter and an already vulnerable family. The reporter's very presence may cause harm, even though they may be behaving responsibly. However, that does not presuppose that the death knock process is a wholly negative experience. Intrusive reporting can produce powerful and effective coverage that can act as a catalyst to public action. It can inform readers of situations which may be beyond their experiences. It can help people who may have undergone a 
similar experience or may do so in the future and it can be cathartic for the interviewees. A poignant example of this occurred during the coverage of the Dunblane massacre when 15 primary school children and their teacher were murdered by Thomas Hamilton. Mrs Lynne McMaster, one of the bereaved parents, told Richard Tait (1996), editor-in-chief of ITN at the time, that she accepted the cameras had to be there. He said:

She had watched other tragedies on television and, as a mother, her heart had gone out to the victims and their families. She had received many messages of comfort from people who had seen her ordeal and she did not feel there had been an invasion of privacy.

Clearly, this was a major incident but the reporting of a single death knock has the potential to engender a similar reaction from readers, viewers or listeners, albeit on a smaller scale.

Indeed, in the authors' own experiences it is well known within the industry that most approaches are met with approval from the family, who are often glad of the opportunity to talk about their loved one and let the community know what has happened. John Griffith (2004) a former newspaper editor who lost his own son in a road accident, says we should not assume the media intrude on grief by contacting the family. He describes the stories that followed his younger son Michael's death as a "great comfort", stating that newspapers containing stories about his son were displayed in his house and visitors were encouraged to read the details of the accident 
and the parents' tribute to him. In effect it meant that the family didn't have to repeat painful details endlessly. His advice to reporters is as follows:

So don't be reluctant to knock on that front door and ask. If families don't want to speak to you, then you can leave. If they do, you will be helping them at a time in their life when they want to feel the wider community cares about them and shares their sorrow. (Griffith, 2004; p37)

Of course, it could be argued that Griffith, as a former newspaper editor and current newspaper executive, would be given "special" treatment by the reporters working for a sector he is involved with. Regardless, his advice is borne out of personal experience. However, there is a sizeable gulf between his guidance and ensuring that the novice reporter who follows it is confident, proficient and sensitive.

\section{Journalists' perceptions of the death knock}

Journalists must make decisions every time they cover a story, and these are often ethical decisions, particularly in the case of the death knock. Consequently, it would be more beneficial for the journalist - and indeed the traumatised interviewee - if these decisions were considered, informed, proactive responses based on understanding a 
situation, thus minimising harm, rather than impetuous, reactive responses to a situation.

It is important therefore that journalism educators should emphasise that essentially reporting a death knock is similar to any other form of news story. Reporters have to apply news values, gather the facts, substantiate them, judge the potential consequences of any actions they take, apply the law and stick to the codes of conduct, then write the piece up accurately and within deadline, all while trying to assess whether the editor will agree with their decisions. However, there are additional pressures, identified in the survey of journalists' attitudes, that can adversely affect this process and these should be pointed out to students. They include having to work through difficult and sensitive ethical decisions by themselves, the increased potential for the journalist to do harm, the unpredictability of a story where the reporter never really knows what kind of emotional response they are going to receive from the family, the sense of anxiety that most reporters, particularly inexperienced ones, feel at having to deal with death and the grieving, and to what extent he or she is intruding on what many would regard as a private time. All of these can have a detrimental effect on the reporter's ability to perform the task. In preparing students or novice reporters for this form of reporting, how can these tensions be recreated effectively in the classroom?

Added to this complex mix are the journalist's own perceptions of the death knock. From the journalists' attitudes survey we established that essentially, they think it is a negative act. They find it stressful because they dislike having to disturb people at a time 
of grief but recognise that they have an obligation to undertake the task. Around half of the respondents considered interviewing traumatised relatives to be an unpleasant task but one that is part of their job. However tellingly, none of the sample group said they would refuse to do such an interview.

Former reporter Geraldine Hayward's description of her experience is fairly typical.

I'd invite myself into your grief, trample around your tortured soul, grab a photograph, and zip back to the office to bang out 300 words of tastefully titillating obituary. You'd think that after repeatedly barging into bereaved relatives' houses, demanding photos of the deceased, and staying until I got at least one killer quote (pardon the pun) out of the living people, that most of these death knocks would stick in my memory. But they don't. I worry that I may be a psychopath. (Hayward, 2005).

It may be that Geraldine Hayward is experiencing a form of dissociation, a mechanism of the brain that enables a person to manoeuvre through "all the potentially upsetting reminders of an earlier traumatic experience without dealing with their full emotional effects" (Cote \& Simpson, 2000).

Terry Pattinson, of the Surrey Herald says: "Reporters, including myself, have returned from "death knocks" with "scoops" and pictures, but the experiences have always left me feeling like a vulture." (Pattinson, 2005) At the very least, reporters have felt low self-esteem and even self-disgust because of the requirement to carry out the 
death knock. Figley (1995) suggests there may be more serious consequences, and that these compound with age, experience and maturity. How do we prepare students for these feelings?

But journalism educators should not only concern themselves with emotional injury when preparing their students for the death knock. Novice reporters are placing themselves in a potentially volatile situation where they could face physical or verbal injury, so as journalism educators should we warn them about this and how far should we go? A sense of perspective can be gained from the journalists' attitudes survey. Although the journalists who participated in the survey found the death knock unpleasant none of them seemed to fear that a violent reaction to their visit could result in them being physically harmed. While they tend not to consider their own personal safety when visiting a traumatised family, they seemed to be more anxious about the emotional effects, for example, some feel under stress because of the unpredictability of how they will be received and what might happen during the interview - and this can affect their reporting. Equally, feelings of dislike and distaste do not diminish with a greater frequency of doing death knocks, and it appears that reporters do not become any more resolved towards it by doing it more often. They may become more proficient but the innate dread of dealing with the bereaved and the erratic nature of the situation seems to remain with them. Recreating this anxiety in the classroom is clearly problematic for journalism educators but it would appear that this sense of stress is a major part of what students need to learn about this form of reporting. 
Yet, few reporters claim to have received any guidance from their editors on the most appropriate actions to take in such situations. A total of $74 \%$ said they were given no advice at all before they were sent to interview a bereaved family. This is possibly because editors believe their reporters are professional and to give such guidance, particularly to experienced reporters, would be patronising. However, editors claim to give more guidance to inexperienced reporters $(50 \%)$ than to experienced reporters (20\%). This perhaps reflects the view among editors that with experience comes the ability to handle complex and difficult situations, which is not necessarily the case with the death knock.

Indeed, there tends to be an underlying assumption that young reporters "learn by doing", that they somehow teach themselves to act with sensitivity and get the story. Indications are that this form of self-learning places pressures on novice journalists in terms of a heightened awareness of causing harm and of performing their role ineffectively, creating a sense of inadequacy or even failure. In our survey of journalists' attitudes, the vast majority (95\%) said that they had not received any training in intrusive reporting from their companies. Of those reporters with three years experience or less none were given any training. So is there an expectation that the novice reporter should learn "on the job", running the risk of experimenting on the bereaved and potentially getting it wrong? Or, is the presumption from the industry that they will be suitably prepared on their journalism courses?

Either way, when the novice reporter returns to the newsroom the speed of the reporting process means there is little opportunity for reflection on the manner in which 
the interview has taken place. Even once deadlines have passed there appears to be limited time available for counselling, discussion or advice on how to improve the process. From the journalists' attitudes survey we learned that none of the editors considered the effect of death knocks on their reporters, suggesting that in the haste of the news reporting process editors do not have time to be concerned about their reporters' emotional state and instead, they tend to rely on them to find a way to cope with the situation. Yet, $96 \%$ of editors believe it is beneficial for a reporter to discuss a death knock with them after the event and are keen to take on this function informally. However, the questionnaire results indicated that there seemed to be an absence of formal counselling facilities within companies and editors lack the training to do this effectively.

It would seem then that generally reporters are left to find their own solutions to best practice in intrusive reporting. For example, $80 \%$ of experienced reporters (those with more than three years' experience) said their personal experience of bereavement helped them professionally. However, only $20 \%$ of inexperienced reporters said their personal experience of bereavement helped them professionally.

While reporters find the death knock to be a negative, distressing experience they take a different view when writing an obituary, even although it involves interviewing bereaved relatives at a stressful time. Writing obituaries is seen as a positive and nonintimidating experience. This would suggest that the reporters' distress is not solely concerned with intruding on the grieving process but in their perception of their role at this time. With an obituary the reporter may perceive themselves to be doing good, 
whereas with the intrusive interview, because their role in the event is less clear cut, they may perceive themselves, albeit subconsciously, as causing harm. Therefore, it would assist students' understanding of the death knock if the positive and negative perceptions of these two forms of intrusive reporting were debated in the classroom.

Journalists were asked in the survey to give their views on training in intrusive reporting. Despite $97 \%$ stating that they thought training for the death knock was important, they as a group had no clear idea of the best way to do this. Only a quarter recommended using a college or university course whereas around one third favoured informal training in the news room. This would suggest that they perhaps feel an understanding of intrusive situations cannot be provided in formal classroom settings but requires a more interactive approach such as role playing or other forms of experiential learning which endeavour to simulate news room practice.

\section{Challenges faced by journalism educators}

There are undoubtedly limitations on the extent to which students can be prepared for the death knock in the classroom, as the survey results acknowledge. In fact it is interesting how few working journalists expect courses to be able to provide effective training in this area. It underlines the most significant challenge for university and college teachers: that they must educate students about the death knock and its consequences in the absence of students' real-life experience. Ethically, and practically, there is no scope for the cohort to engage in this practice until they are working 
professionally, unlike the experiential learning provided for court and council reporting, for instance. To re-create the challenges of the death knock, and ape the industry's afore-mentioned preference for "learning by doing", the tutor would have to subject the student to what could be extreme emotional stress, a position at odds with the institution's duty of care to students. Each student's personal experiences of death and bereavement would also have to be accounted for in order to prepare them adequately. In setting out to provide a "safe" environment for students we may also be providing one that is sterile and impotent in terms of the learning experience. But while it is important that we consider ways of providing active simulations such as role play in relatively safe environments, we should also acknowledge, perhaps as a starting point, that the classroom does have certain advantages in preparing novice journalists for the death knock, offering the time and space for debate and reflection that the industry seemingly cannot.

It was strongly suggested in the survey that journalists' distress is related to their negative or positive perceptions of their role in interviewing the bereaved, rather than a global aversion to intruding into grief. It should follow that having more knowledge about the positive outcomes of the death knock, having robust ideas about the ethics of the situation, and talking about and reflecting on the interview process in general, and intrusive interviewing specifically, within the classroom, should improve the journalists' confidence and feelings of self-efficacy and justification in approaching the task. Arguably, if this was all we could do as educators, it would help make the death knock a more acceptable task, reducing the stress on the journalist involved. Undergraduate 
and, to a more limited extent, postgraduate journalism courses already have the means to do this within the law, ethics and practice modules, and there is already evidence of elements of good practice from the interviews. Most lecturers and students believed there was scope for more development of debate and reflection, although concerns were raised during the interviews with journalism educators about the viability of such work in the FE and private sector, where "fast track" courses which already have a packed curriculum are often the norm.

As well as providing a level of theoretical initiation to the death knock, death itself and the consequent grief, it may also be possible to give novice journalists a greater sense of control over their actions in terms of knowing why they are there, when to approach, what to say, and when to withdraw, through the teaching of codes of conduct and increased exposure to the experiences of both working journalists and the victims themselves.

One of the observations from the interviews was that the educational practice of situating teaching about the ethics of the death knock within professional and practical concerns is seen as vital by students, who would like to see more "blurring of the boundaries" between theory and practice in this area. There was some criticism of the "straight" teaching of codes of conduct without specific reference to current cases and without practical applications. However, most academics made reference to the use of such recent cases as the Rhys Jones murder in ethics teaching as well as in the practical courses. Participants also confirmed that talking about the ethics of the death knock and the reception you are likely to get from bereaved relatives does help to build some 
confidence in students. One participant, who studied attitudes to the death knock in the newsroom as a dissertation subject, said that the more she had studied the subject, the better she felt about the process.

People don't realise that some people may want to speak to journalists. In the classes your eyes are opened to that a little bit. You realise people maybe aren't going to be huddled in a corner with all the windows and doors shut hiding from reporters. I think that aspect is important, but again it is limited.

Another former student complained that real debate on the issue wasn't "opened out" enough in his undergraduate class because few of the students could imagine themselves in such a position, few had any experience, and most were appalled at the thought of it. For him, this lack of classroom rigour was a failing in his education that perhaps delayed his ethical thinking about the death knock until he began working. He believes that if discussion had been more thorough, and if working journalists had come in to argue the point, he may have developed a more critical understanding of the process which was less wrapped up with emotion and pre-judgements. Current students involved in the focus group felt the inclusion of a talk by a victims' group followed by an open debate had been helpful in developing their understanding of both the reporter's role and the family's likely feelings in such potentially intrusive situations. 
It gave us a chance to bridge a gap in our experience. I think we were all very uncomfortable when they came in, but as soon as we realised they were willing to talk about it, it made a difference.

On the issue of empowering young journalists to feel en element of control in their approach to the death knock, there were mixed views. Interestingly, the two former students who had roughly equivalent experiences, working for a news agency, had very different perceptions of the amount of control they had over the situation, perhaps giving credence to the view that personality type could be an important factor in the way death knocks are handled. Former student A felt "very little control" in that situation: "Always the person in control was X (news editor). Like he was in control and I was the person responsible for making sure his control got executed." By contrast former student B's response to the same situation was much more assertive and assured:

You have to make a decision early on in your career about how you're going to deal with things, and it doesn't make you a good or bad reporter. I don't buy into this thing that you do anything for the job because you still have to sleep at night. 
Background, age and confidence should perhaps also be seen as variables in this perception of control. In this case the more self-assured reporter was older, in his thirties when he joined the degree course, and was therefore more experienced in negotiating his terms of work and work practices. By contrast, the reporter who felt very little control had come to university straight from A-levels. Arguably this questions the established practice of sending young reporters on death knocks, sometimes "to see how they cope" (Fleming et al, 2006) and reflects the findings of the journalists' attitudes survey where most inexperienced reporters said they received no training and only limited advice in reporting the death knock.

The practice of offering practical tips to help an inexperienced reporter negotiate the death knock was less well received than the idea of expanding reflection and debate. All participants who discussed this agreed there is only so far you can go with the advice. One participant described such tips as a framework for students to "latch on to" provided by the recounted experience of the lecturers and working reporters. One lecturer said the framework should be very basic, comprising general advice such as "accept a cup of tea" etc, because the encounter is often a very fraught affair between a distressed relative and an often scared journalist. All tutors interviewed agreed that the best advice to students about the situation is to do what they feel comfortable with. This view was supported by the former students interviewed, with former student $C$ believing that "technique" is down to the individual. She argues that although it is possible to give some advice on body language, nothing should be "set in stone" because of the personal nature of people's responses. As she points out: "Everyone has 
their own way, and it would be very difficult to judge that and suggest one was a success and the other a failure". Of course it could also be seen as unethical or at least manipulative to try to teach "persuasive" body language and approach techniques to journalists dealing with bereaved relatives. Victims' representative B observed that an honest approach from a genuinely sympathetic reporter is the one most likely to succeed.

Former student B warns lecturers not to complicate what is already a very difficult situation with a host of do's and don'ts. Trying to negotiate the death knock while also remembering to practise the psychology of body language could be too much for a young reporter to bear, he says.

If you, who've done death knocks, sat down with a student and said, 'Trevor, this is what you need to do. You need to be empathic; you need to remain cool; you need to maintain eye contact; you need to be warm,' you'd have the young lad panicking. ......The first death knock you ever do is horrendous.

All current students in the focus group felt that their university study had increased their levels of competence and confidence in approaching the death knock through general reporting instruction and experience. They were able to see interviewing the bereaved as a "scary and emotional" extension of their normal practice. One said that in becoming a more competent journalist, he felt he would be 
able to approach the family more professionally and ask better, more sensitive questions.

\section{Role-play as an approach}

While acknowledging the contribution which can be made by analysis, reflection and debate in the classroom, there is still the question of whether the academy can facilitate any "learning by doing" in this area. The survey results have established that the self-learning expected of the novice journalist carrying out death knocks and other intrusive interviews places them under great stress in terms of a heightened awareness of causing harm and of performing their role ineffectively. Much could be achieved, then, by improving the novice's feelings of self-efficacy both in terms of reporting generally and intrusive reporting specifically through some sort of active learning.

Role play is an established part of most journalism courses, and would seem to be the obvious tool through which to offer students practical experience. The National Council for the Training of Journalists programmes have featured role play in both formative and summative assessment, and most journalism degree courses include some form of role play, particularly in first level writing and reporting classes. These tend to present quite varied but more emotionally mundane scenarios than the "death knock", with lecturers routinely masquerading as police officers, nurses, vicars etc. Role plays are usually used within the first year of education or training, and tend to test the student's ability to "see" the story, ask the right questions, and cover all the angles. 
Social skills are commented on, but are not a main criterion. In the case of a role play involving bereavement these priorities would arguably have to be reversed, making it a much more complex and personal task for both the actor/tutor and student, and one for which the tutor may feel ill-equipped, even without the added complication of ethics and authenticity brought on by attempting to mimic someone in extreme grief.

At present there is little more than patchy, anecdotal information on the efficacy of such methods in journalism education. However, academics and trainers in the fields of medicine, counselling, management theory, social work and sales have documented both concerns about and plaudits for the use of role play in professional training. Although the experiences of students and trainees in these areas would not be directly replicated in journalism, they do offer us some pointers as to how appropriate a tool role play is, and what the advantages and disadvantages of certain approaches may be. Problems include those of authenticity, of trainee resistance to playing roles, and the risk of unintentionally undermining students who may feel they have "failed" in the role. (Test, 1994; Fertleman et al, 2005; Lambourn, 2005.) Resource issues can also present a challenge, either in terms of classroom time or financial outlay to "buy in" expert help. A number of studies warn of the potentially negative effects of role play in the classroom. Test (1994) challenges both the authenticity of the setting and the legitimacy of role play as a training tool when time for learning is limited. The author, a sales and marketing specialist, points out that mistakes made in the classroom have a critical audience, unlike mistakes made in the field. Those made in the field are unobserved, and so give the trainee the opportunity to reflect and learn from them. By contrast 
observed mistakes in the classroom can make the trainee nervous, which then impacts negatively on future performance. Swink (1993) agrees that role plays in which trainees can make mistakes in front of their peers are rarely popular with learners.

Larson et al (1998) looked at how perceived performance in role play affected views of self-efficacy among students on a counselling course. Bandura's social cognitive theory was applied to both the modelling of good counselling practice and to role play carried out by the students themselves in an attempt to gauge whether their perceived success in the exercises improved feelings of self-efficacy, suggested by Bandura as necessary for their future development as practitioners. The researchers found that the effect of using a videotape to 'model' the counselling experience, in which a 'best practice' session was filmed and shown to students, produced a modest but uniformly beneficial improvement in trainees' reports of self-efficacy. By contrast the role play intervention produced far more "volatile" results, with trainees who viewed their performance as a great success increasing their self-efficacy score significantly, while those who viewed their performance as mediocre reported a sharp decrease in selfefficacy, demonstrating a potential negative effect of the technique.

Interviews with journalism educators revealed a number of concerns about the use of role play in teaching about the death knock. Those participants who had had experience of such role play, portraying a bereaved parent for an exercise, or having hired actors to role play, or both, were unhappy with the outcome in terms of authenticity and effectiveness. 
I think they found it difficult to separate me out from me the lecturer and me the grieving mother. I think they're too embarrassed by it as well. I don't think they particularly like acting out in front of their colleagues.

Other journalism educators had grave doubts about the effectiveness of role play generally, and felt there was a particular danger in younger students not taking the exercise seriously. As there are no ethical means of introducing students to the real-life death knock, some felt we were teaching them in something of a "vacuum", to which perhaps examples and discussion were the most sensible answer, rather than a practical task which may lack credibility.

There was general agreement that what separates the death knock from an ordinary interview is the "intense atmosphere". Whether the role play was done by a lecturer or an actor, it would be almost impossible to recreate this atmosphere in the classroom because the students would still not be dealing with real victims. Only one of the former students interviewed thought that role play could be useful to forewarn students about the emotional intensity of the death knock. Although he thought such exercises would be limited in terms of re-creating the actual situation, when often you are "shaking like a leaf", he did believe we should try to "instil some of that fear into the students" to faithfully reproduce the challenges of work in the field. In terms of the ethical stance of universities, SEDA and other such advisory bodies, this would be extremely difficult to justify in the classroom, but it nevertheless points out one of the tensions between academe and industry. Interestingly, this participant was unsure 
whether actors would be a better idea than lecturers recreating the scene, for the simple reason that lecturers were likely to have much first-hand experience of the death knock, whereas actors almost certainly wouldn't.

Other former students who were interviewed, and all current students involved in the focus group discussion, were unconvinced about the efficacy of role play. They were particularly concerned about students' ability to take such a re-enactment seriously, and also echoed lecturers' concerns about students being too self conscious to concentrate fully on the task. Former student B highlighted another major concern for educationalists, that in trying to recreate the death knock, the perceived lack of authenticity involved could spread to students' and industry's views of the course as a whole.

You get this thing in HE where some people accuse it of being wet - it's because of these re-enactments. I really don't believe them..... An actor may be very good at portraying grief on stage or on TV for an audience, but it isn't real. How do you possibly portray a mum who has lost her only daughter to some mass rapist who's dragged her off, done despicable things to her and left her in a ditch somewhere? I don't want to be negative about it. I think training is a very positive thing, but in this one situation I don't see how it would work. 
One of the victims' representatives interviewed echoed this point, saying role play was a laudable idea, but one that would not be particularly effective in preparing students for the harsh reality.

I think it's something you can never rehearse. You can explain how to approach families, and we can explain how we are likely to be feeling when something like that happens, but everybody reacts differently.

It could be said that the most compelling case against role play is in terms of costbenefit analysis. Most participants agreed with the findings of Larson (1998) that the exercise could be undermining, would have to be carefully placed in the programme, and would need to be repeated more than once to offset negative effects and allow time for reflective learning. As one participant argued, repeated role play is necessary from a pedagogical point of view so that students could "go through the process and make mistakes and then benefit from the feedback on that".

This gives us problems in two specific areas: resources and time. As all the lecturers participating said they would prefer to use actors, but would struggle to fund even one session, it makes role play in the present courses problematic. All lecturers participating complained that they were already struggling to find room in the curriculum for the necessary academic and practical skills, particularly as all worked on courses accredited by the National Council for the Training of Journalists, which itself makes heavy demands on the curriculum. 


\section{Conclusion}

It has become clear from the issues discussed in this article that reporting a death knock is far from the routine newsgathering process of covering more general news. Essentially the techniques may be the same but the approach requires greater sensitivity, keener moral decision-making and a mature attitude and as a result reporting a death knock is extremely complex.

Journalists must make decisions on every story they cover, but the potential to do harm clearly is greater when a reporter is in an intrusive situation. Interviewees are in a highly emotional state. Equally, the journalist may be battling to keep their anxieties under control. As a result the journalist could misread signals, utter a careless word, or make a poor decision about a course of action. Given the subjective nature of the situation journalists find themselves in and the unpredictable human element it is little wonder that tensions, conflict and contradictions arise both on the part of the journalist and the interviewee, and students should be made aware of these. That said, we as journalism educators should be cautious of over-emphasising the fear factor about reporting death and intrusion into grief and shock. We should be careful to emphasise the similarities to other forms of news as well as the differences in order to boost students' confidence and their sense of control by giving them a familiar starting point. Additionally, discussions of the characteristics of trauma should take place in the classroom in order to give students an awareness of them but lecturers would be ill- 
advised to attempt to teach students to recognise clinical signs of trauma. Giving students a list of signs to look out for during an interview would only increase their anxiety. Equally, it may be useful to students to discuss the emotional impact that undertaking intrusive stories can have on them, immediately and at a later stage, and to reassure them that it is appropriate for them to feel these.

Death is part of life and it is the journalist's role in society to reflect life. Journalists do consider the death knock a negative act but perhaps it is possible over time to change attitudes to this form of reporting. Notifying people of an individual's death is an "old and valued tradition" where the dead are "praised for their good deeds, not their faults" (Williams, 2003; Alali, 1993). Although these comments relate to obituaries they are applicable to intrusive reporting too and as identified earlier journalists take a more positive attitude to writing an obituary than a death knock story. Therefore, there is no reason why a death knock should not focus on the deceased's "good deeds", giving novice reporters the opportunity to view the death knock more positively. Williams (2003) notes: "Obituaries are a part of grief management; they are social frames that represent death in a very limited way to others." She adds:

Obituaries represent cultural responses to death. Beliefs and attitudes about death are framed in obituaries or death announcements where the focus is often on the deceased and on the living. Obituaries, in many respects, represent the framing of a final linkage between the deceased and the living. Obituaries are life's final social frame. 
Therefore, when teaching students about the death knock, we as journalism educators should place the emphasis on the important, positive elements of constructing "life's final social frame" and assisting in "grief management" for an individual and their family. If their tuition in intrusive reporting were to focus on these elements then perhaps students and novice reporters would perceive their role in the process differently as doing good. Indeed it may be as journalism educators we are culpable of focusing students on the negative aspects such as intrusion, fear, anxiety, when we could tackle these tensions in the classroom by providing our students with a more optimistic framework from which to approach the death knock.

Also, by deconstructing issues such as intrusion, fear and anxiety within a more positive context rather than telling students horror stories of our own death knock experiences as young reporters we may be able to able to make these issues/concerns sufficiently familiar to students that their problematic nature is diminished. As a result novice reporters may gain a sense of control over why they undertake a death knock, what to say and when to withdraw. Discussing these issues and other ethical matters such as moral justification for intrusive reporting, consequences of the journalist's actions, and duty to the job, may equip students to make informed, proactive decisions rather than impetuous responses, thus minimising harm.

Additionally, however, it may be valuable for students to have a sense of the stress and anxiety journalists can feel when doing this type of reporting. Recreating this anxiety in an educational setting which is expected to be an essentially safe 
environment is problematic, not least of all in risk assessment terms. It is unlikely that the true sense of nervousness experienced by reporters can be recreated in any simulation, however, experiential learning methods such as virtual learning environments (VLE) where the student works through a computer simulation at their own pace may be close to the real thing. However, such programmes are resource intensive to design. Despite its problems, role playing may provide limited exposure to the tensions experienced in this form of reporting, if only for the student playing the journalist.

Clearly though, this stress is a major part of what students need to learn about the death knock, and it is something that the surveyed journalists tended to feel should be undertaken in the news room environment. In these days of reduced editorial personnel perhaps this is not a realistic prospect. However, at the root of this point may be a recognition that it is important for reporters to have gained some basic editorial experience and an awareness of journalism's responsibilities to society before they are taught about the death knock. There is, after all, an expectation that novice reporters learn by doing on the job and whilst having students undertake real death knocks as a learning strategy is highly problematic we can teach them the techniques of learning by doing, or reflection in action and on action. Teaching them to critically reflect, not only on specialist modules like Media Ethics, but across the curriculum will assist them in identifying the stress points in their reporting and in taking appropriate, positive action, thus giving them greater control over the situation. Therefore, it would be advisable to 
place teaching intrusive reporting at an advanced level on undergraduate degrees and on postgraduate degrees. 


\section{References}

ADAMS, SALLY (2001) Interviewing for Journalists, London: Routledge

ALALI, A. ODASUO (1993) "Management of Death and Grief in Obituary and in Memoriam Pages in Nigerian Newspapers" Psychological Reports, Vol 73 pp. $835-42$

CAMERON, JACKIE (2007) "Journalism and Trauma” MSc Research Report, Institute of Work Psychology, University of Sheffield

DANT, GARETH (1998) “Knocking on Death's Door”, Press Gazette (April 24)

\section{p.14}

FERTLEMAN CAROLINE, GIBBS JAMES, EISEN SARAH (2005) “Video improved role play for teaching communication skills", Medical Education, November 39 (11), pp.1155-6.

FIGLEY, CHARLES R. (Ed) (1995) Compassion fatigue: Coping with secondary traumatic stress disorder in those who treat the traumatized, New York: Brunner/Mazel

FLEMING, CAROLE; HEMMINGWAY, EMMA; MOORE, GILLIAN AND WELFORD, DAVE (2006) An Introduction to Journalism, London: Sage GRIFFITH, JOHN (2004) "Private Grief, Public Kindness", Insight Magazine, Winter 2004, p.37

HAYWARD, GILLIAN (2005) “At Death's Door”, Press Gazette, January 2005 KEEBLE, RICHARD (2001) Ethics for Journalists, London: Routledge LAMBOURN, ROBERT (2005) "Teaching Problem Consultations: A Comparison of Two Approaches Using Videotaped Simulated Consultations in One-to- 
one Teaching Involving (A) The Trainer Role-Playing and (B) The Use of Drama Students", Education for Primary Care, Vol 16, pp.192-205

LARSON, LISA M. (1998) "The social cognitive model of counselor training", The Counseling Psychologist, 26, pp.219-73.

PATTINSON, TERRY (2005) "The Good, the Bad, and the Ones Who Nick Your Fags", Press Gazette, February 4, 2005

SIMPSON, ROGER AND COTE, WILLIAM (2006) Covering Violence, A Guide to Ethical Reporting About Victims and Trauma ( $2^{\text {nd }}$ ed), New York: Columbia University Press

SWINK, D. F. (1993) "Role-Play Your Way to Learning", Training and Development, May, pp.91-7

TAIT, RICHARD (1996) in "Dunblane: Reflecting Tragedy, A report by the British Executive International Press Institute", London, British Executive International Press Institute, pp. 31-3

TEST, ALAN (1994) "Why I Do Not Like to Role Play", American Salesman, August, Vol 39 Issue 8, pp.7-11

WILLIAMS, JOYCE E. (2003) "Obituraries" Handbook of Death and Dying, Sage Publications, http://sage-reference.com/death/Article n68.html, accessed 23 March 2009 


\section{Notes on Contributors}

Dr Sallyanne Duncan is programme director of the MLitt in Journalism programme at the Strathclyde School of Journalism and Communication at the University of Strathclyde, Glasgow, Scotland. Her research interests focus on the reporting of events involving trauma, bereavement or anxiety, particularly concerning the individual family. Her doctoral thesis examined the pressures placed on, and the processes undertaken by, journalists who cover intrusive stories such as large-scale disasters, and more commonly, personal traumatic experiences.

Contact details: Strathclyde School of Journalism and Communication, Department of English Studies, University of Strathclyde, 26 Richmond Street, Glasgow, G1 1XH, Scotland

Tel: +44 (0)1419503553

Email: sallyanne.duncan@strath.ac.uk 